Check for updates

Cite this: RSC Adv., 2019, 9, 5958

Received 8th November 2018 Accepted 1st February 2019

DOI: 10.1039/c8ra09241a

rsc.li/rsc-advances

\section{Effect of metal-doped VPO catalysts for the aldol condensation of acetic acid and formaldehyde to acrylic acid}

\author{
Yumeng Wang, Yuelin Hou, Xue Hao, Zhenlu Wang (D) and Wanchun Zhu (D)*
}

Mo, W, Cr, La, and Ce additives were introduced into a VPO catalyst, and the resulting catalysts were investigated for the gas-phase aldol condensation reaction of formaldehyde and acetic acid. XRD, FT-IR, SEM, $\mathrm{NH}_{3}-\mathrm{TPD}, \mathrm{Py}-\mathrm{IR}$, and BET were used to characterize the structure and properties of the catalysts. After the addition of the third component, the crystal structure changed to a certain extent; the surface acidity of the catalyst changed, and the conversion of acetic acid and the selectivity of acrylic acid also showed different degrees of influence. The acidity of the catalyst was the main factor affecting the catalytic performance. When La was added to the catalyst, the selectivity for acrylic acid was the highest, and the stability of the catalyst also improved. It is presumed that B acid is the main active site of this reaction, and a moderate amount of acid is favorable to facilitate the reaction.

\section{Introduction}

Acrylic acid, which is an important raw material and resin monomer for organic synthesis, is widely used in the construction industry, textile industry, packaging products, sanitary materials, etc. ${ }^{1-5}$ The methods to produce acrylic acid include cyanoethanol hydrolysis (alcoholysis), ${ }^{6}$ acetylene carbonylation, $^{7-11}$ acrylonitrile hydrolysis, ${ }^{\mathbf{1 2}}$ and propylene oxidation. ${ }^{13-16}$ Among them, the propylene oxidation technology has long been established and is widely used by companies in various countries. However, since the 1970 s, faced with the rise in oil prices and the oversupply of methanol and acetic acid in coal chemical products, a process using condensation of acetic acid and formaldehyde to produce acrylic acid has emerged. This is a non-petroleum synthetic route and has numerous potential applications.

The aldol condensation reaction of acetic acid and formaldehyde produces mainly acrylic acid and water but is also accompanied by side reactions, producing acetone, carbon dioxide, methyl acetate, etc. Current research shows that the catalyst system with better activity is a vanadium phosphorus oxide catalyst. ${ }^{17-25}$ As the study progressed, it was found that the introduction of other components into the VPO catalyst significantly improved the catalytic performance. There are two methods used: one is to restore $\mathrm{V}^{5+}$ first and then introduce, and the other includes introduction of the precursor after preparation.

Key Laboratory of Surface and Interface Chemistry of Jilin Province, College of Chemistry, Jilin University, Jiefang Road 2519, Changchun, 130021, P. R. China. E-mail: wczhu@jlu.edu.cn; Fax: +86 0431 85168420; Tel: +86043188964193
Mamoru $\mathrm{Ai}^{26}$ proposed the introduction of $\mathrm{Si}(\mathrm{V} / \mathrm{P} / \mathrm{Si}=1 / 2 /$ 2.2) and $\mathrm{Ti}(\mathrm{V} / \mathrm{Ti} / \mathrm{P}=1 / 2 / 5)$ into the $\mathrm{V}_{2} \mathrm{O}_{5}-\mathrm{P}_{2} \mathrm{O}_{5}$ system. To conduct the acrylic acid reaction, the catalyst performances are ranked as $\mathrm{V} / \mathrm{Ti} / \mathrm{P}>\mathrm{V} / \mathrm{P}>\mathrm{V} / \mathrm{Si} / \mathrm{P}$.

In the patent of Jianren Tai, ${ }^{27}$ organic titanium (including titanium lactate, titanium alkanolamine, and titanium acetylacetonate), which can be dissolved in water and has redox activity, is mixed with vanadium and phosphorus. By the modification of the alkali metal, the surface area of the catalyst is increased, and the acidity of the catalyst is improved. It has a high catalytic performance in the reaction of formaldehyde and acetic acid. After calculation on the basis of acetic acid, the yield of acrylic acid can reach $33.7 \%$.

Zhang et al. ${ }^{28}$ loaded lanthanum onto a VPO catalyst for the reaction of methyl acetate and formaldehyde. The introduction of La improves the stability of the reaction, avoids changes in the vanadium valence, and improves the performance of the catalyst. A transition metal, such as molybdenum, is introduced into the VPO catalyst for the reaction of methanol with acetic acid. The yield of the target product acrylic acid can reach $80 \% .^{29}$ D. Nagaki ${ }^{30}$ introduced cesium salt and tungsten salt into the VPO catalyst. The obtained catalyst was used for the aldol condensation of formaldehyde and acetic acid to increase the conversion of acetic acid.

In order to further improve the activity and selectivity of the catalyst, the influence of the promoter on the structural properties of the catalyst and the performance of the catalytic reaction was examined. In our present work, MVPO (M: Mo, W, Cr, $\mathrm{La}, \mathrm{Ce}$ ) catalysts were prepared and used in the reaction of acetic acid and formaldehyde to prepare acrylic acid. The structures and properties of the catalyst were confirmed by XRD, FT-IR, SEM, $\mathrm{NH}_{3}$-TPD, Py-IR, BET, etc. The relationships among the 


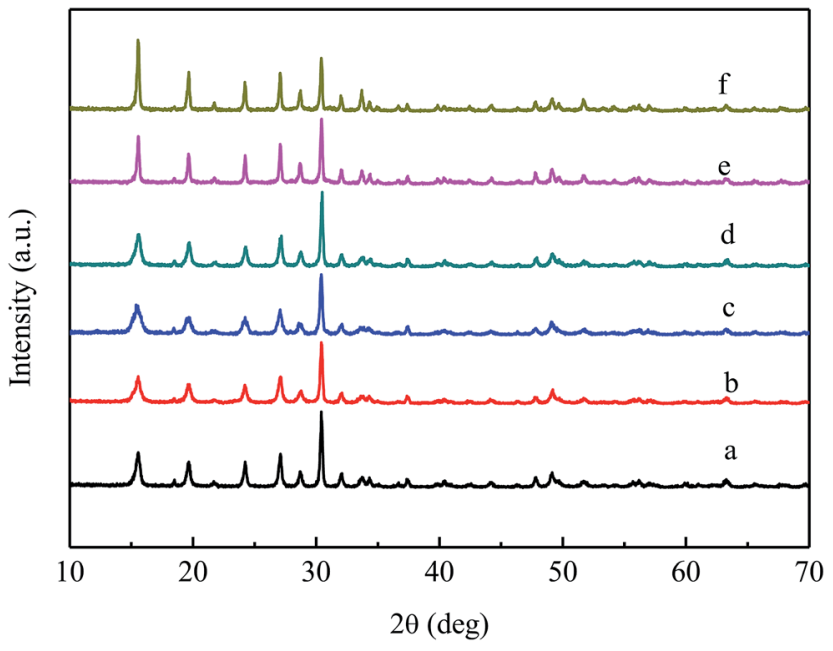

Fig. 1 XRD patterns of VPO and MVPO precursors. (a) VPO; (b) MoVPO; (c) WVPO; (d) CrVPO; (e) LaVPO; (f) CeVPO.

compositions, structural properties and reaction performances of the catalysts were discussed.

\section{Experimental}

\subsection{Catalyst preparation}

MVPO catalysts were prepared by the organic route as described below. ${ }^{19,24,25} \mathrm{~V}_{2} \mathrm{O}_{5}(5 \mathrm{~g})$ was refluxed for $4 \mathrm{~h}$ at a certain temperature $\left(110{ }^{\circ} \mathrm{C}\right)$ in a mixture of benzyl and isobutyl alcohols. After the temperature of the solution decreased to $50{ }^{\circ} \mathrm{C}$, appropriate amounts of the metal salt of component $\mathrm{M}$ (the $\mathrm{M} / \mathrm{V}$ molar ratio was 0.06/1) and orthophosphoric acid were added. After refluxing for four hours, the obtained suspension was filtered and then dried at $100{ }^{\circ} \mathrm{C}$ overnight to yield the desired catalyst precursor. The catalyst precursor was calcined under air atmosphere at $550{ }^{\circ} \mathrm{C}$ for five hours to obtain a catalyst. The prepared catalyst was named as MVPO (M: Mo, W, Cr, La, Ce).

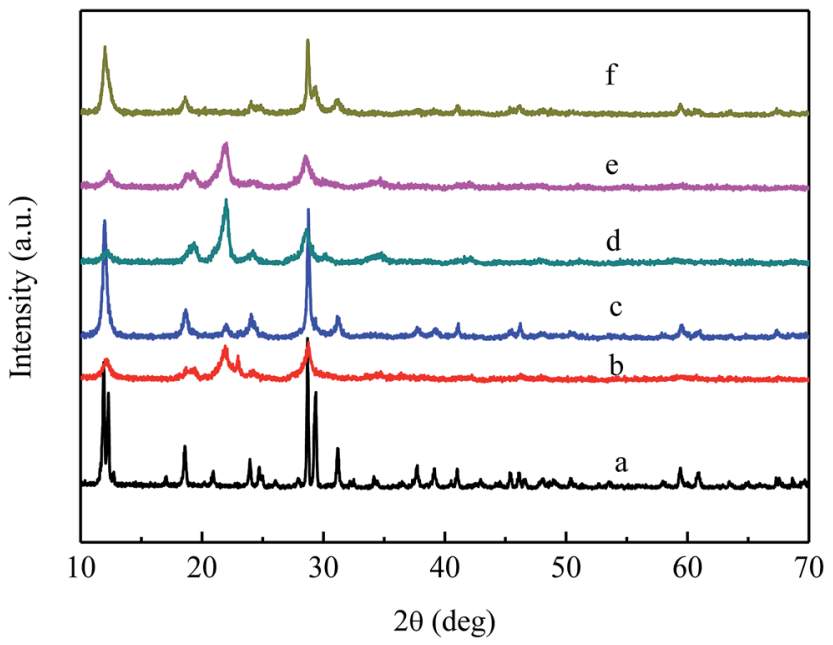

Fig. 2 XRD patterns of VPO and MVPO catalysts. (a) VPO; (b) MoVPO; (c) WVPO; (d) CrVPO; (e) LaVPO; (f) CeVPO.

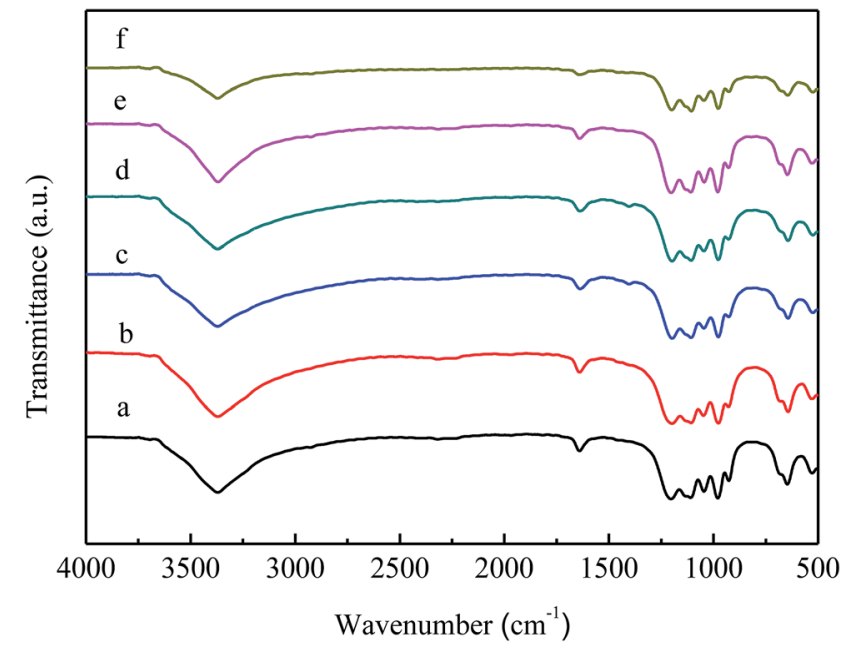

Fig. 3 FT-IR spectra of VPO and MVPO precursors. (a) VPO; (b) MoVPO; (c) WVPO; (d) CrVPO; (e) LaVPO; (f) CeVPO.

\subsection{Catalyst characterization}

Powder X-ray diffraction (XRD) was carried out using a Shimadzu XRD-6000 diffractometer with $\mathrm{Cu}-\mathrm{K} \alpha$ radiation. The catalysts were operated at $30 \mathrm{kv}$ and $40 \mathrm{~mA}$ with a scan step of $10^{\circ} \mathrm{min}^{-1}$ in the $2 \theta$ range from 10 to $70^{\circ}$.

Fourier transform infrared spectroscopy (FT-IR) was performed with a Nicolet Impact 410 spectrometer to record the infrared characteristic absorption peaks of the catalysts. The solid samples were prepared using $\mathrm{KBr}$ as a diluent and detected in the wavenumber range of $4000-400 \mathrm{~cm}^{-1}$.

Topographical information was obtained by a JSM-6700F scanning electron microscope (SEM).

The acidity of catalysts was measured by the temperature programmed desorption of $\mathrm{NH}_{3}\left(\mathrm{NH}_{3}\right.$-TPD). The ChemBET Pulsar TPR/TPD device was used with helium as a carrier gas and detected using a TCD detector. Also, $50 \mathrm{mg}$ catalyst was thermally treated at $550{ }^{\circ} \mathrm{C}$ with flowing $\mathrm{N}_{2}$ for $30 \mathrm{~min}$ and then

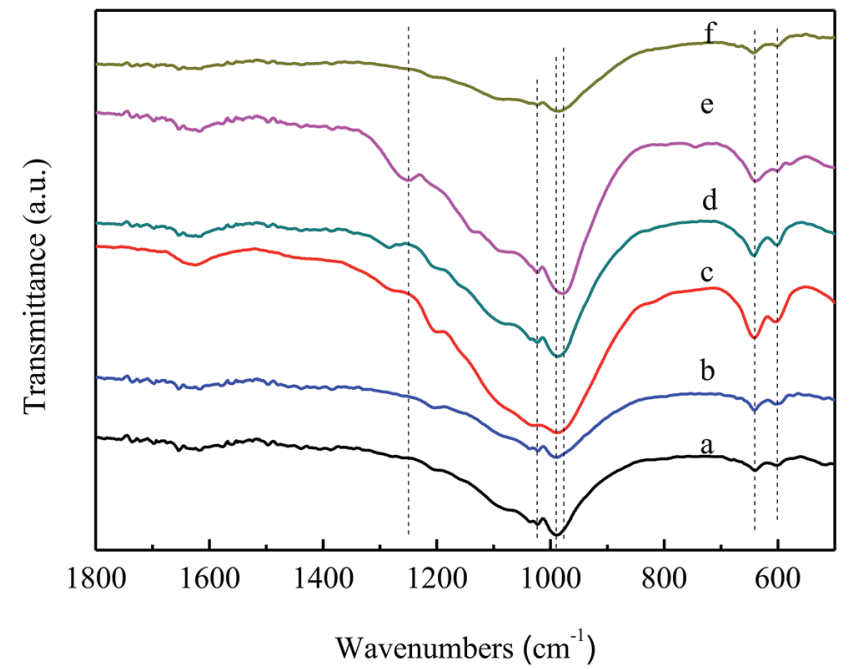

Fig. 4 FT-IR spectra of VPO and MVPO catalysts. (a) VPO; (b) MoVPO; (c) WVPO; (d) CrVPO; (e) LaVPO; (f) CeVPO. 


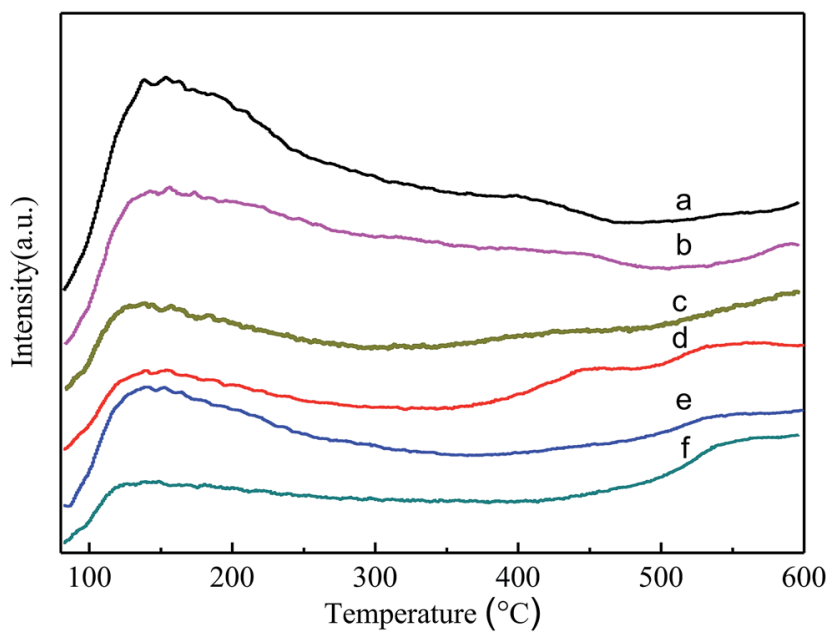

Fig. $5 \mathrm{NH}_{3}$-TPD patterns of VPO and MVPO catalysts. (a) VPO; (b) LaVPO; (c) CeVPO; (d) MoVPO; (e) WVPO; (f) CrVPO.

cooled to $80{ }^{\circ} \mathrm{C}$ prior to adsorption. After that, the sample was purged with He to remove physical adsorption. After the baseline was stable, the system was heated from $80{ }^{\circ} \mathrm{C}$ to $800{ }^{\circ} \mathrm{C}$ with a heating rate of $10{ }^{\circ} \mathrm{C} \mathrm{min}^{-1}$. The amount of chemisorbed ammonia was detected with a TCD detector.

Pyridine adsorption infrared spectroscopy (Py-IR) was performed with a self-made pyridine adsorption infrared device.
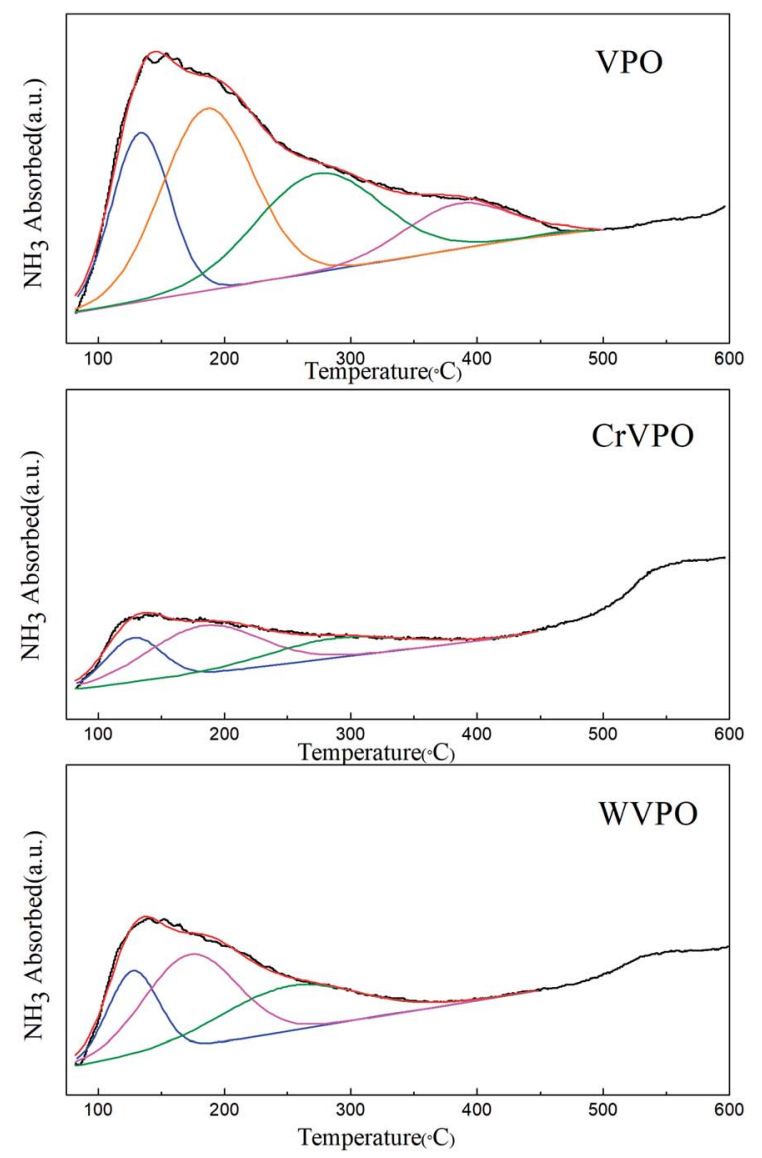

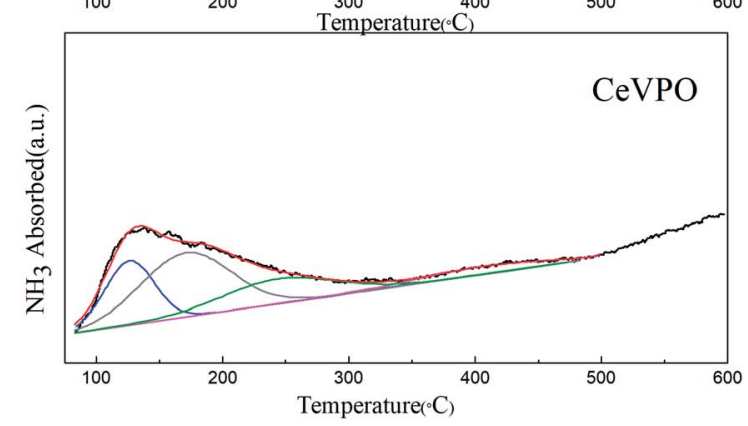

After the catalyst was pressed into a pure tablet, it was fixed in a pyridine adsorption infrared cell (the device was evacuated) and heated to $473 \mathrm{~K}$ for 30 minutes for pretreatment. Afterwards, the temperature was lowered to room temperature; pyridine adsorption was performed for $30 \mathrm{~min}$, and vacuum desorption was performed at room temperature for 10-15 min. The catalyst was heated to $373 \mathrm{~K}$ or $473 \mathrm{~K}$ under vacuum for 30 minutes to allow desorption, and it was finally tested at room temperature.

Hydroxyl infrared spectroscopy (OH-IR) was performed with a Nicolet Impact 410 spectrometer. The catalyst was compressed and fixed in the infrared sample cell. After the device was evacuated to a high vacuum, the temperature was increased to $373 \mathrm{~K}, 473 \mathrm{~K}$ and $623 \mathrm{~K}$ for 30 minutes. After cooling to room temperature, the infrared absorption peak of the sample was tested.

The total surface area and pore structure of the catalysts were measured in a Micromeritics ASAP 2010 instrument. After the sample was dehydrated under vacuum at $473 \mathrm{~K}$, it was tested at $77 \mathrm{~K}$ in a liquid nitrogen atmosphere. The BET method was used to calculate the specific surface area and the BJH method was used to calculate the pore distribution.

\subsection{Catalytic evaluation}

The activity of the condensation of acetic acid and formaldehyde to acrylic acid was evaluated in a fixed bed flow reaction
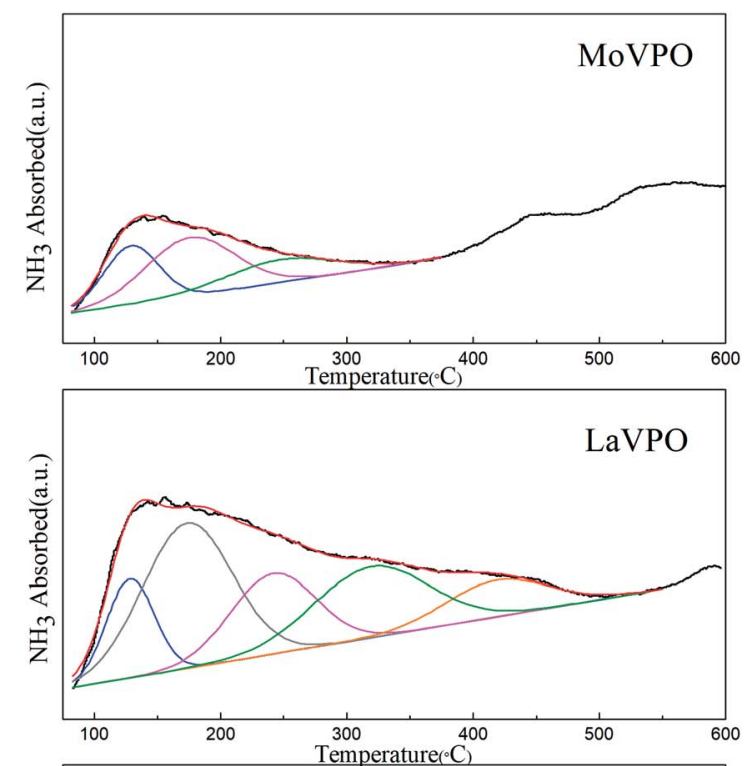

Fig. 6 Peak fitting results of the $\mathrm{NH}_{3}$-TPD profiles of MVPO catalysts. 
system. The reaction material was triacetaldehyde dissolved in acetic acid solution. The reaction product was analyzed by gas chromatography on-line and quantified by the internal standard method. The relevant calculation formula is as follows:

The conversion of acetic acid (HAc):

$$
C_{\mathrm{HAc}}=\frac{n_{\text {initial HAc }}-n_{\text {residual HAc }}}{n_{\text {initial HAc }}} \times 100 \%
$$

The selectivity of acrylic acid (AA):

$$
S_{\mathrm{AA}}=\frac{n_{\text {produced AA }}}{n_{\text {initial HAc }}-n_{\text {residual HAc }}} \times 100 \%
$$

The yield of acrylic acid (AA):

$$
Y_{\mathrm{AA}}=C_{\mathrm{HAc}} S_{\mathrm{AA}} \times 100 \%
$$

\section{Results and discussion}

\subsection{XRD analysis}

The XRD patterns of VPO and MVPO precursors are shown in Fig. 1. All of the precursors have diffraction peaks at $15.5^{\circ}$, $19.6^{\circ}, 24.1^{\circ}, 27.0^{\circ}, 28.6^{\circ}, 31.9^{\circ}, 33.6^{\circ}, 34.3^{\circ}, 37.4^{\circ}, 47.7^{\circ}, 49.1^{\circ}$, and $63.4^{\circ}$, which are attributed to the $\mathrm{VOHPO}_{4} \cdot 0.5 \mathrm{H}_{2} \mathrm{O}$ (JCPDS 84-0761) phases. Among them, the diffraction lines at $2 \theta=15.5^{\circ}$ and $31.9^{\circ}$ correspond to the (001) and (220) crystal planes of $\mathrm{VOHPO}_{4} \cdot 0.5 \mathrm{H}_{2} \mathrm{O}$. It can be seen from the figure that the (220) planes of each precursor are preferentially grown. The intensity of the characteristic peaks of the (001) planes of the precursors to which the scandium and yttrium components are added

\begin{tabular}{|c|c|c|c|}
\hline Catalyst & $\begin{array}{l}\text { Peak center } \\
\left({ }^{\circ} \mathrm{C}\right)\end{array}$ & Peak area & $\begin{array}{l}\text { Proportion } \\
\text { (\%) }\end{array}$ \\
\hline \multirow[t]{4}{*}{ VPO } & 133.8 & 81.0 & 22.50 \\
\hline & 186.5 & 137.9 & 38.32 \\
\hline & 273.8 & 101.4 & 11.02 \\
\hline & 384.6 & 39.7 & 28.16 \\
\hline \multirow[t]{3}{*}{ CrVPO } & 128.3 & 20.2 & 23.69 \\
\hline & 183.6 & 43.9 & 51.49 \\
\hline & 287.0 & 21.2 & 24.82 \\
\hline \multirow[t]{5}{*}{ LaVPO } & 128.4 & 39.1 & 12.95 \\
\hline & 173.6 & 107.8 & 35.71 \\
\hline & 241.8 & 56.6 & 18.76 \\
\hline & 319.3 & 67.4 & 22.31 \\
\hline & 418.8 & 31.0 & 10.27 \\
\hline \multirow[t]{3}{*}{ MoVPO } & 129.2 & 26.5 & 29.74 \\
\hline & 175.9 & 42.5 & 47.60 \\
\hline & 247.6 & 20.2 & 22.66 \\
\hline \multirow[t]{3}{*}{ WVPO } & 127.7 & 35.5 & 22.67 \\
\hline & 173.1 & 70.6 & 45.08 \\
\hline & 252.2 & 50.5 & 32.25 \\
\hline \multirow[t]{4}{*}{ CeVPO } & 126.3 & 26.1 & 24.95 \\
\hline & 171.0 & 47.5 & 45.36 \\
\hline & 243.7 & 22.9 & 7.81 \\
\hline & 405.1 & 8.2 & 21.88 \\
\hline
\end{tabular}
increased relatively. It can be concluded that the crystal phase

Table $1 \mathrm{NH}_{3}$-TPD results of MVPO catalysts

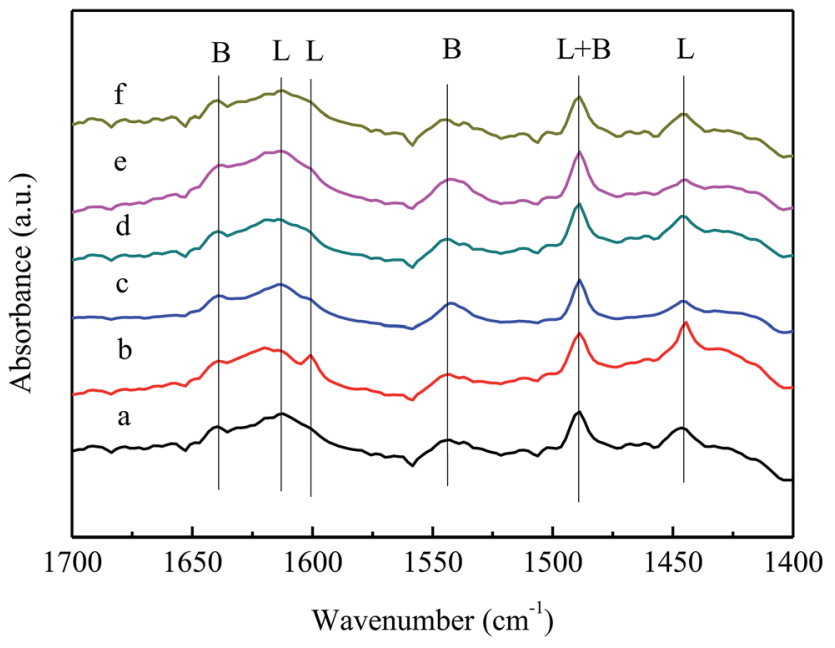

Fig. 7 Py-IR spectra of VPO and MVPO catalysts. (a) VPO; (b) MoVPO; (c) WVPO; (d) CrVPO; (e) LaVPO; (f) CeVPO.

composition of precursors with different additives is consistent, and $\mathrm{La}$ and $\mathrm{Ce}$ additives have a certain role in improving the microcrystalline phase structure of the precursor. ${ }^{31}$

Fig. 2 shows the XRD patterns of the VPO and MVPO catalysts; a represents the XRD pattern of the VPO catalyst. The diffraction lines at $2 \theta=11.9^{\circ}, 18.6^{\circ}, 23.9^{\circ}, 28.7^{\circ}, 31.2^{\circ}, 37.8^{\circ}$, $41.1^{\circ}$, and $42.6^{\circ}$ were typical of the $\mathrm{VOPO}_{4} \cdot 2 \mathrm{H}_{2} \mathrm{O}$ (JCPDS $36-$ 1472) phase.

The curves of (b-f) show the XRD patterns of VPO catalysts with different components. It can be seen from the figure that the addition of different components has different effects on the crystal phase of the catalyst. The diffraction peaks of (b) at $22.0^{\circ}, 24.2^{\circ}, 28.5^{\circ}, 34.7^{\circ}$, and $42.0^{\circ}$ were attributed to the characteristic peak of the $\delta$-VOPO 4 (JCPDS 47-0951) phase, and the characteristic peaks appearing at $11.9^{\circ}$ and $28.7^{\circ}$ were typical of the $\mathrm{VOPO}_{4} \cdot 2 \mathrm{H}_{2} \mathrm{O}$ (JCPDS 27-0949) phase. The strong diffraction peaks of (c) and (f) at $11.9^{\circ}, 18.6^{\circ}, 23.9^{\circ}, 28.7^{\circ}, 31.2^{\circ}$, $37.8^{\circ}, 41.1^{\circ}$, and $42.6^{\circ}$ belonged to the $\mathrm{VOPO}_{4} \cdot 2 \mathrm{H}_{2} \mathrm{O}$ (JCPDS $36-$

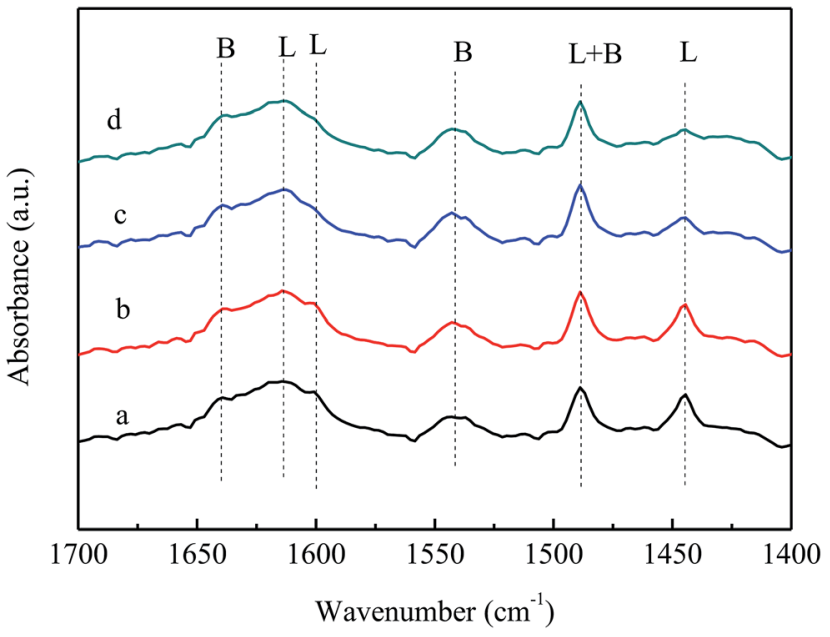

Fig. 8 Py-IR spectra of LaVPO with different desorption temperatures. (a) LaVPO- $25{ }^{\circ} \mathrm{C}$; (b) LaVPO- $100{ }^{\circ} \mathrm{C}$; (c) LaVPO-150 ${ }^{\circ} \mathrm{C}$; (d) LaVPO$200^{\circ} \mathrm{C}$. 
1472) phase. The diffraction lines of $\mathrm{d}$ at $2 \theta=19.5^{\circ}, 22.0^{\circ}, 24.2^{\circ}$, $28.5^{\circ}, 34.7^{\circ}$, and $42.0^{\circ}$ were typical of the $\delta-\mathrm{VOPO}_{4}$ (JCPDS $47-$ 0951) phase. The diffraction peaks of (e) at $19.5^{\circ}, 22.0^{\circ}, 24.2^{\circ}$, $28.5^{\circ}, 34.7^{\circ}$ and $42.0^{\circ}$ were attributed to the characteristic peak of the $\delta-\mathrm{VOPO}_{4}$ (JCPDS 47-0951) phase, and the characteristic peaks appearing at $11.9^{\circ}$ and $28.7^{\circ}$ were typical of the $\mathrm{VOPO}_{4}$ $\cdot 2 \mathrm{H}_{2} \mathrm{O}$ (JCPDS 36-1472) phase.

In summary, the crystal phases of the VPO, CeVPO and WVPO catalysts belonged to the $\mathrm{VOPO}_{4} \cdot 2 \mathrm{H}_{2} \mathrm{O}$ (JCPDS 36-1472) crystal phase. The crystal phase of the Cr-added catalyst belonged to the $\delta$ - $\mathrm{VOPO}_{4}$ (JCPDS 47-0951) crystal phase. The crystal phases of MoVPO and LaVPO catalysts belonged to the mixed crystal phase of $\delta$-VOPO 4 (JCPDS 47-0951) and $\mathrm{VOPO}_{4} \cdot 2 \mathrm{H}_{2} \mathrm{O}$ (JCPDS 27-0949) crystal phases.

\subsection{FT-IR analysis}

Fig. 3 shows the FT-IR spectra of VPO and MVPO precursors. All precursors exhibited infrared absorption peaks at $3371 \mathrm{~cm}^{-1}$, $1646 \mathrm{~cm}^{-1}, 1199 \mathrm{~cm}^{-1}, 1105 \mathrm{~cm}^{-1}, 1045 \mathrm{~cm}^{-1}$ and $641 \mathrm{~cm}^{-1}$. The band at $3371 \mathrm{~cm}^{-1}$ belongs to the stretching vibration absorption peak of $\mathrm{O}-\mathrm{H}$. The peaks appearing at $1646 \mathrm{~cm}^{-1}$ are attributed to the bending vibration absorption peaks of the coordinated water molecules. The bands at $1199 \mathrm{~cm}^{-1}$,

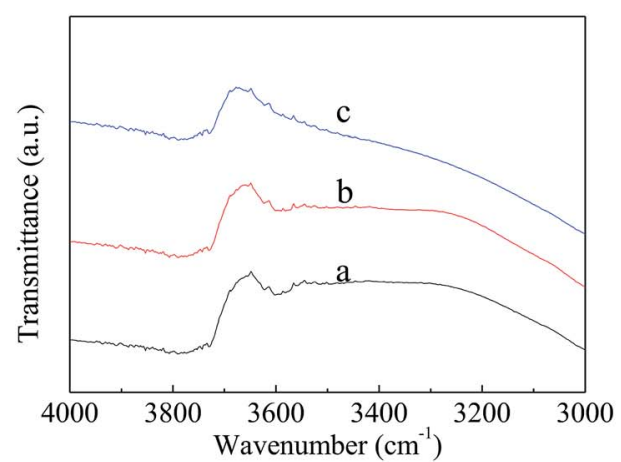

(A)

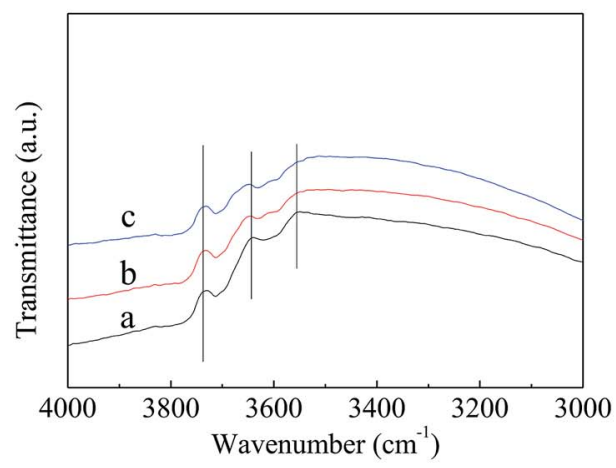

(C)

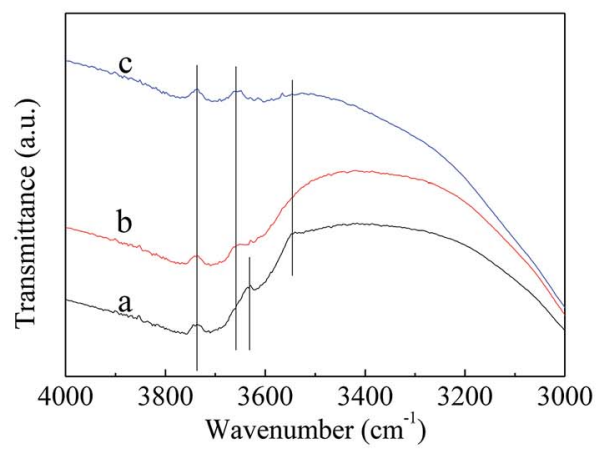

(E)

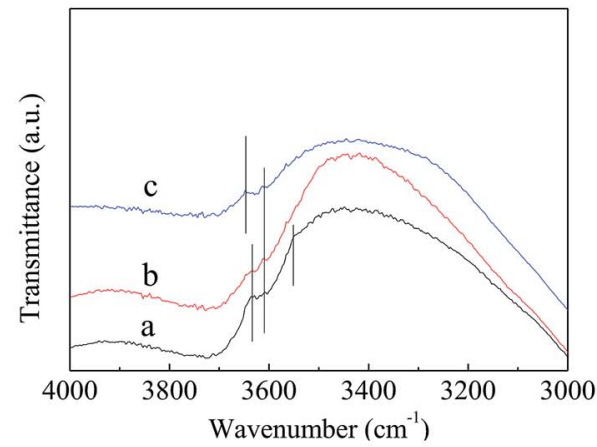

(B)

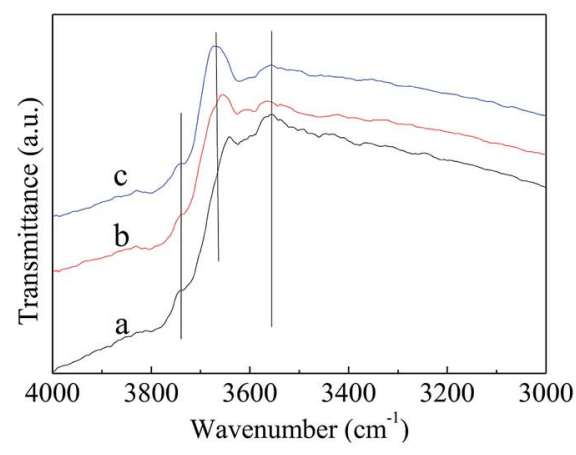

(D)

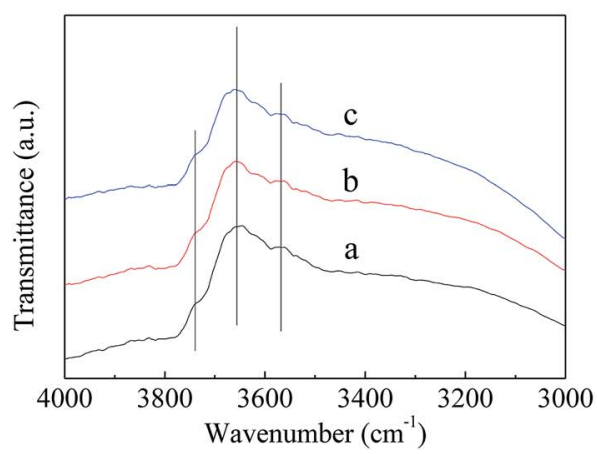

(F)

Fig. $9 \mathrm{OH}-I R$ spectra of VPO and MVPO catalysts with different processing temperatures. (A) VPO; (B) MoVPO; (C) WVPO; (D) CrVPO; (E) LaVPO; (F) CeVPO. (a) $100{ }^{\circ} \mathrm{C}$; (b) $200^{\circ} \mathrm{C}$; (c) $350{ }^{\circ} \mathrm{C}$. 
$1105 \mathrm{~cm}^{-1}$, and $1045 \mathrm{~cm}^{-1}$ are the asymmetric stretching vibration absorption peaks of $\mathrm{PO}_{3}$. The bands at $977 \mathrm{~cm}^{-1}$ and $641 \mathrm{~cm}^{-1}$ correspond to the stretching vibration absorption peak of $\mathrm{V}=\mathrm{O}$ and the bending vibration absorption peak of $\mathrm{P}-$ $\mathrm{OH}$. This is consistent with the infrared spectrum of the $\mathrm{VOHPO}_{4} \cdot 0.5 \mathrm{H}_{2} \mathrm{O}$ crystal phase. ${ }^{31}$

Fig. 4 shows the FT-IR spectra of VPO and MVPO catalysts. All catalysts exhibited infrared absorption peaks at $1244 \mathrm{~cm}^{-1}$, $1023 \mathrm{~cm}^{-1}, 990 \mathrm{~cm}^{-1}, 975 \mathrm{~cm}^{-1}, 644 \mathrm{~cm}^{-1}$ and $606 \mathrm{~cm}^{-1}$. The peak at $1244 \mathrm{~cm}^{-1}$ belongs to the stretching vibration absorption peak of $\nu(\mathrm{PO})_{3}$. The bands at $1023 \mathrm{~cm}^{-1}$ are attributed to the stretching vibration absorption peaks of $\mathrm{V}=\mathrm{O}$. The absorption peaks at $990 \mathrm{~cm}^{-1}, 975 \mathrm{~cm}^{-1}$, and $606 \mathrm{~cm}^{-1}$ belong to the $\mathrm{P}-\mathrm{O}$ and $\mathrm{V}-\mathrm{O}$ stretching vibration absorption peaks of $\mathrm{VOPO}_{4}$ and $\mathrm{VOPO}_{4} \cdot 2 \mathrm{H}_{2} \mathrm{O}$. The peaks appearing at $644 \mathrm{~cm}^{-1}$ are attributed to the bending vibration absorption peaks of $\mathrm{P}-\mathrm{OH}$.

\section{3 $\mathrm{NH}_{3}$-TPD analysis}

Fig. 5 shows the $\mathrm{NH}_{3}$-TPD comparison of the VPO and MVPO catalysts with desorption temperatures from 80 to $600{ }^{\circ} \mathrm{C}$. The peak fitting results of the $\mathrm{NH}_{3}$-TPD profiles are shown in Fig. 6 and summarized in Table 1 . As shown in the figure, the $\mathrm{NH}_{3}$ desorption peaks for all the catalysts appear at temperatures in the range of $80-300{ }^{\circ} \mathrm{C}$, which correspond to the weak and middle-strong acid sites. ${ }^{32,33}$ Among them, a wide range of $\mathrm{NH}_{3}$ desorption peaks appear at $350-500{ }^{\circ} \mathrm{C}$ for (a), (b), and (c) (VPO, LaVPO, and CeVPO), which correspond to strong acid sites. For the LaVPO catalyst, the proportion of strong acid sites is the largest $(32.58 \%)$. To investigate the type of acid sites of the catalysts, they were further analyzed by pyridine infrared absorption spectroscopy.

\subsection{Py-IR analysis}

To investigate the type of acid sites on the VPO catalyst and the third component-added catalyst, we performed Py-IR characterization of VPO, MoVPO, WVPO, CrVPO, LaVPO, and CeVPO catalysts. Fig. 7 shows the pyridine infrared spectra of the VPO catalyst and the MVPO catalysts. According to the literature ${ }^{34-36}$ the absorption peaks at $1445 \mathrm{~cm}^{-1}, 1595 \mathrm{~cm}^{-1}$, and $1611 \mathrm{~cm}^{-1}$ belong to $\mathrm{L}$ acid sites, the absorption peaks at $1640 \mathrm{~cm}^{-1}$ and $1540 \mathrm{~cm}^{-1}$ are attributed to $\mathrm{B}$ acid sites, and the absorption peaks at $1480 \mathrm{~cm}^{-1}$ are the common adsorption sites of $\mathrm{L}$ acid and $\mathrm{B}$ acid. For the VPO catalyst, the $\mathrm{L}$ acid sites are provided by the coordination unsaturated $\mathrm{V}$ ions and the $\mathrm{B}$ acid sites are provided by $\mathrm{P}-\mathrm{OH} .^{37}$

As shown in Fig. 7, the peak position of the pyridine absorption peak of the VPO catalyst after the addition of the third component did not change, indicating that the type of catalyst acid center did not change. The peak intensities of (c) and (e) (WVPO and LaVPO) at $1445 \mathrm{~cm}^{-1}$ decreased, indicating that the introduction of $\mathrm{W}$ and La reduced the quantities of $\mathrm{L}$ acid. The intensity of (b) (MoVPO) peak is strong, indicating that the introduction of Mo increases the quantities of $\mathrm{L}$ acid and $\mathrm{B}$ acid.

Fig. 8 shows the pyridine infrared spectrum of the LaVPO catalyst at different desorption temperatures. It can be seen that as the desorption temperature increases, the peak position of the pyridine absorption peak does not change, the peak intensity slightly decreases, the number of $\mathrm{L}$ weak acid sites decreases, and the $\mathrm{B}$ acid remains stable.

\subsection{OH-IR analysis}

In order to further study the acidity of the catalyst surface, the above catalysts were characterized by in situ hydroxyl infrared spectroscopy. Fig. 9 shows the OH-IR spectra of different catalysts treated at $100{ }^{\circ} \mathrm{C}, 200{ }^{\circ} \mathrm{C}$ and $350{ }^{\circ} \mathrm{C}$. As the temperature increases, some hydroxyl peaks disappear and some hydroxyl peaks remain. The disappearing hydroxyl peak belongs to a hydroxyl group that adsorbs water molecules or hydrogen bonds. The steady state of the infrared hydroxyl peak is attributed to the isolated hydroxyl group on the catalyst surface.

At the same time, the results also showed that the $\mathrm{OH}$ position on the catalyst surface significantly increased after the third component was added to the VPO catalyst. The hydroxyl peak of the catalyst was relatively stable when the temperature of VPO, WVPO, LaVPO, and CeVPO catalysts was increased from $200{ }^{\circ} \mathrm{C}$ to $350{ }^{\circ} \mathrm{C}$. The previous determination of the pyridine infrared spectroscopy indicated that the $\mathrm{B}$ acid center is relatively stable because the $\mathrm{B}$ acid site is predominantly $\mathrm{P}-\mathrm{OH}$. The
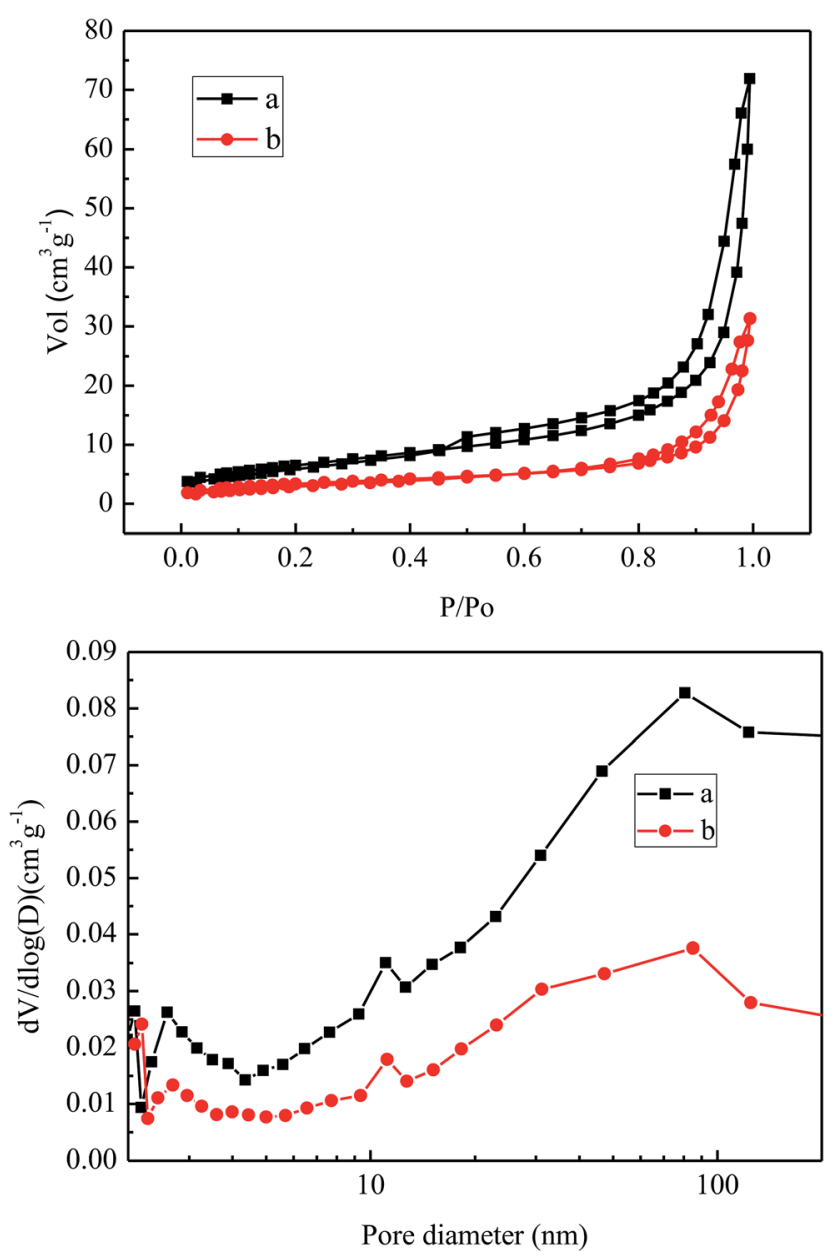

Fig. 10 Pore size distribution curves of VPO and LaVPO catalysts. (a) VPO; (b) LaVPO. 
Table 2 The structure parameters of VPO and LaVPO catalysts

\begin{tabular}{llll}
\hline Samples & $\begin{array}{l}\text { BET surface } \\
\text { area }\left(\mathrm{m}^{2} \mathrm{~g}^{-1}\right)\end{array}$ & Pore vol. $\left(\mathrm{cm}^{3} \mathrm{~g}^{-1}\right)$ & $\begin{array}{l}\text { Pore size } \\
(\mathrm{nm})\end{array}$ \\
\hline VPO & 21.61 & 0.0582 & 10.35 \\
LaVPO & 10.79 & 0.0277 & 9.94 \\
\hline
\end{tabular}

pyridine infrared results are consistent with the hydroxyl infrared results.

\subsection{BET surface area analysis}

Fig. 10 shows the nitrogen adsorption and desorption isothermal curves of the VPO catalyst and LaVPO catalyst. It can be seen from the figure that the adsorption amount of $\mathrm{a}$ is larger. According to the literature, both are typical type IV isothermal adsorption desorption curves. The $\mathrm{H}_{2}$-type hysteresis loop, which occurs at $P / P_{\mathrm{o}}$ of $0.8-0.98$, consists of nonuniform nanoparticles arranged to form an "ink-bottle"-shaped hole with a wide distribution of holes. From Table 2, it can be seen that the introduction of La reduces the specific surface area of the catalyst and reduces the pore volume and the average pore size. ${ }^{38}$

\subsection{SEM analysis}

Fig. 11 shows the SEM micrographs of VPO and LaVPO catalysts. As shown in Fig. 11a and c, the VPO and LaVPO precursors exhibit a rose-like structure. The VPO catalyst after roasting in a muffle furnace showed a rose-like structure that changed to produce some particulate debris. However, the LaVPO catalyst after roasting in the muffle furnace maintained a rose-like structure. It is speculated that the introduction of La has a certain role in stabilizing the structure of the catalyst.

\subsection{Catalytic performance evaluation}

The catalytic performance of VPO and MVPO catalysts is presented in Table 3. The introduction of the third component into the VPO catalyst has a certain influence on the condensation reaction of formaldehyde and acetic acid. Compared to the observations for the VPO catalyst, the conversion of acetic acid and the selectivity of acrylic acid on the catalyst with the $\mathrm{Cr}$ component decreased significantly. The conversion of acetic acid on the MoVPO catalyst slightly increased, but the selectivity of acrylic acid decreased significantly. The selectivity of acrylic acid on the WVPO, LaVPO and CeVPO catalysts increased, and the LaVPO catalyst exhibited better selectivity of acrylic acid than the other catalysts.

Combining XRD results, we inferred that the crystal phases of VPO, CeVPO and WVPO catalysts belonged to the $\mathrm{VOPO}_{4} \cdot 2 \mathrm{H}_{2} \mathrm{O}$ (JCPDS 36-1472) crystal phase. The crystal phase of the Cr-added catalyst belonged to the $\delta$-VOPO 4 (JCPDS $47-$ 0951) crystal phase. The crystal phases of MoVPO and LaVPO catalysts belonged to the mixed crystal phase of $\delta-\mathrm{VOPO}_{4}(\mathrm{JCPDS}$ 47-0951) and $\mathrm{VOPO}_{4} \cdot 2 \mathrm{H}_{2} \mathrm{O}$ (JCPDS 27-0949) crystal phases. It

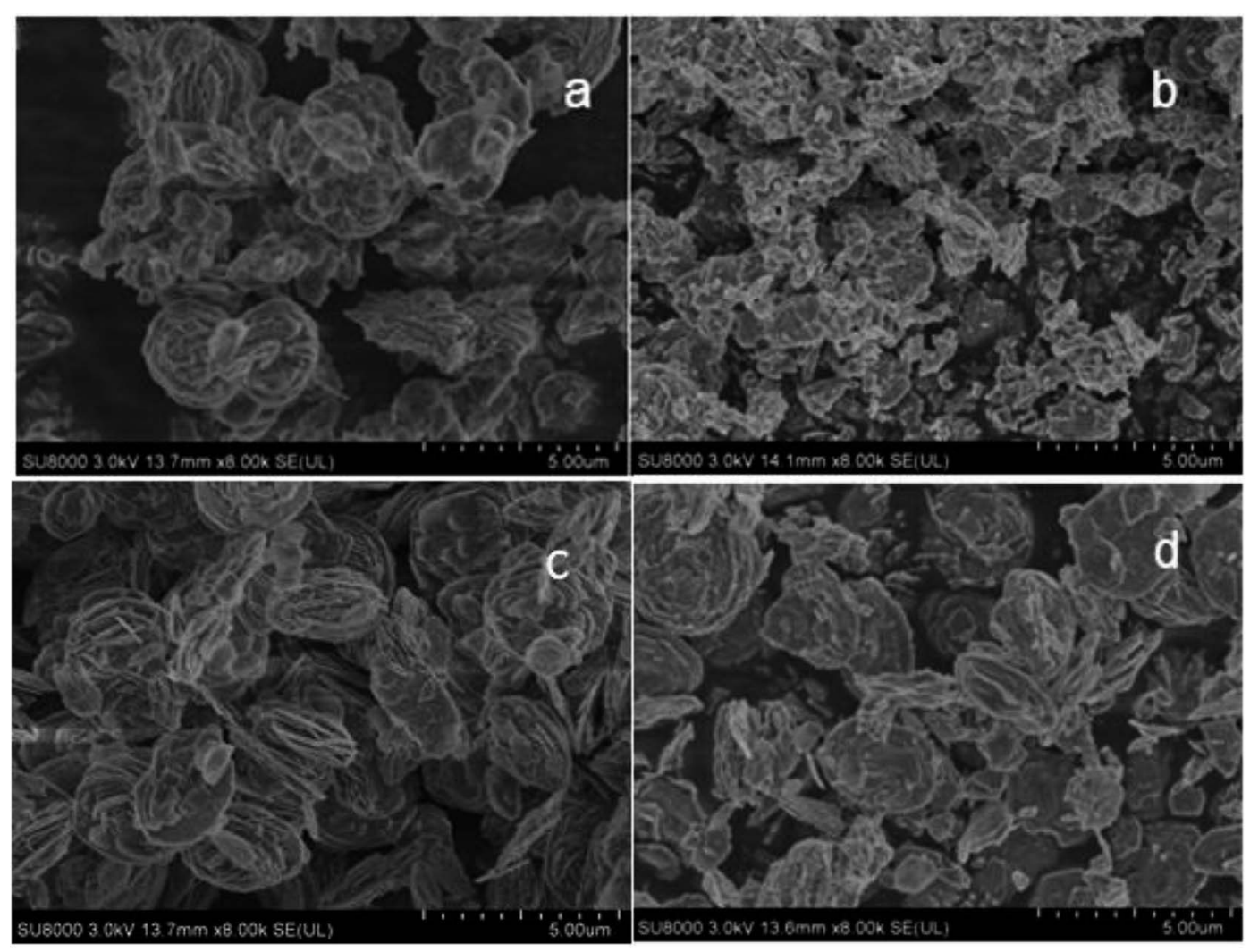

Fig. 11 SEM photos of VPO and LaVPO catalysts. (a) VPO (precursor); (b) VPO; (c) LaVPO (precursor); (d) LaVPO. 
Table 3 Catalyst performance of VPO and MVPO catalysts with different components ${ }^{a}$

\begin{tabular}{llll}
\hline Catalyst & $\begin{array}{l}\text { Conv. of HAc } \\
(\%)\end{array}$ & Selec. of AA $(\%)$ & $\begin{array}{l}\text { Yield of AA } \\
(\%)\end{array}$ \\
\hline VPO & 27.5 & 63.9 & 17.6 \\
MoVPO & 29.8 & 49.1 & 14.2 \\
WVPO & 27.0 & 72.9 & 19.7 \\
CrVPO & 12.6 & 57.5 & 7.2 \\
LaVPO & 22.4 & 76.6 & 17.2 \\
CeVPO & 28.9 & 70.5 & 20.4
\end{tabular}

${ }^{a}$ The reaction conditions: amount of catalyst, $1 \mathrm{~mL}$; calcination temperature, $550{ }^{\circ} \mathrm{C}$; calcination atmosphere, muffle furnace; $\mathrm{HAc} / \mathrm{FA}$ $=3.5 / 1$; volume of feedstock, $1 \mathrm{~mL} \mathrm{~h}^{-1}$; the flow of $\mathrm{N}_{2}, 20 \mathrm{~mL} \mathrm{~min}^{-1}$; the flow of $\mathrm{O}_{2}, 3 \mathrm{~mL} \min ^{-1}$; space velocity, $2400 \mathrm{~h}^{-1}$; reaction temperature, $350{ }^{\circ} \mathrm{C}$ (HAc: acetic acid; AA: acrylic acid; FA: trioxymethylene).

can be seen that the crystal structure changes after adding the third component, but the crystal phase structure does not have a clear relationship with the selectivity of the target product on the catalyst.

After combining the results of $\mathrm{NH}_{3}$-TPD and Py-IR, we could report the following conclusions. The VPO catalyst and the MoVPO, LaVPO, and CeVPO catalysts have weak acid, medium strong acid, and strong acid centers, while the WVPO and CrVPO catalysts have weak acid and medium strong acid centers. This shows that the introduction of different components has different effects on the acidity and the quantity of the VPO catalyst. The quantity of L acid in the LaVPO and WVPO catalysts decreased significantly, but the catalytic performance was better. It is speculated that B acid is the main active site of this reaction. The amounts of $\mathrm{L}$ acid and $\mathrm{B}$ acid in the MoVPO catalyst greatly increased, but the selectivity of the target product was poor, indicating that a moderate amount of acid is favorable for the reaction.

\section{Conclusions}

After adding the third component, the VPO catalyst exhibited a certain change in the crystal phase structure, but its crystal phase structure showed negligible relationship with the selectivity of the target product on the catalyst. The type of acid on the surface of the catalyst, the amount of acid, and the stability of the acid sites also changed. The conversion of acetic acid and the selectivity of acrylic acid also have different degrees of influence on the catalyst.

When the La component was added to the catalyst, the selectivity of acrylic acid on the catalyst was the highest (76.6\%). The LaVPO catalyst's crystal phase belonged to the mixed crystal phase of $\delta$-VOPO ${ }_{4}$ (JCPDS 47-0951) and $\mathrm{VOPO}_{4} \cdot 2 \mathrm{H}_{2} \mathrm{O}$ (JCPDS $27-$ 0949) crystal phases. The specific surface area, pore volume, and average pore size of the catalysts were all reduced.

The acidity of the catalyst is a major factor affecting the catalytic performance of the catalyst. The quantity of $\mathrm{L}$ acid in the LaVPO and WVPO catalysts decreased significantly, but the catalytic performance was better. It is speculated that B acid is the main active site of this reaction. The amounts of $\mathrm{L}$ acid and $\mathrm{B}$ acid in the MoVPO catalyst greatly increased, but the selectivity of the target product was poor, indicating that a moderate amount of acid is favorable for the reaction.

\section{Conflicts of interest}

There are no conflicts to declare.

\section{Acknowledgements}

This work was supported by Shanghai Huayi Acrylic Acid Co., Ltd.

\section{References}

1 Z. J. Zhang, Q. H. Wang, M. A. Jian-Xue and X. D. Chu, Guangzhou Chem. Ind., 2012, 40, 57-62.

2 B. Z. Qian, Shanghai Chem. Ind., 2010, 35, 34-36.

3 X. Y. Guo, Y. Li, H. B. Liang, L. Liu and X. X. Liu, Mod. Chem. Ind., 2011, 31, 6-8.

4 L. F. Cui and Z. Y. Hou, Chem. Ind., 2012, 30, 21-24.

5 Y. X. Lu, Fine Spec. Chem., 2014, 22, 1-6.

6 X. L. Liang, L. W. Zheng, X. Wang and W. B. Wang, Chem. Adhes., 2014, 36, 298-301.

7 W. Qiu, Y. B. Wang and Z. H. Wei, J. Salt Chem. Ind., 2013, 42, 23-25.

8 X. M. Zhang and X. Zhou, Chin. J. Synth. Chem., 2012, 20, 399-402.

9 H. T. Neher, E. H. Specht and A. Neuman, Preparation of Acrylic Esters, US Pat., 2582911, 1952.

10 X. X. Shi, H. S. Tian and Y. F. Zhu, Guangdong Chem. Ind., 2008, 35, 30-34.

11 W. Reppe and R. Stadler, Process Producing Acrylate Acid, US Pat., 3023237, 1962.

12 P. Zhang and Z. H. Wang, Evaluation and Comparison of Several Main Technological Processes for Production of Acid/ Acrylic Ester Abroad and Some Superficial Views on Future Development of $A A / A E$ in China (I), Chem. Ind. Press, 2003, vol. 8.

13 Z. Y. Xie, Shanghai Chem. Ind., 2006, 31, 40-44.

14 X. G. Yang, Z. T. Liu and J. Q. Zhang, Nat. Gas Chem. Ind., 1998, 23, 43-47.

15 N. Nojiri, Y. Sakai and Y. Watanabe, Catal. Rev.: Sci. Eng., 1995, 37, 145-178.

16 A. Tenten, F. G. Martin and H. Hibst, Multimetal Oxide Masses, Eur. Pat., 668104(A1), 1995.

17 R. A. Schneider, Synthesis of Acrylic Acid and Esters, US Pat., 4165438, Albany, Calif, 1979.

18 R. A. Schneider, Catalyst for a $n$-Butane Oxidation to Maleic Anhydride, US Pat., 3864280, Berkeley, Calif, 1975.

19 K. Katsumoto and D. M. Marquis, Method of Preparing Vanadium(IV) Phosphate Composition with High Intrinsic Surface Area, US Pat., 4132670, 1979.

20 M. AI, J. Catal., 1987, 107, 201-208.

21 M. AI, J. Catal., 1988, 112, 194-200.

22 M. AI, J. Catal., 1987, 107, 201. 
23 In Proc. 9th Intern Congress on Catalysis, ed, M. AI, Ottawa, 1988.

24 H. S. Horowitz, C. M. Blackstone, A. W. Sleight and G. Teufera, Appl. Catal., 1988, 38, 193-210.

25 L. M. Cornaglia, C. A. Sanchez and E. A. Lombardo, Appl. Catal., A, 1993, 95, 117-130.

26 M. AI, J. Catal., 1990, 124, 293-296.

27 J. Tai and R. J. Davis, Catal. Today, 2007, 11, 1-8.

28 Z. Q. Zhang and H. F. Wang, A Supported P, V, Cs, La Catalyst and Its Application, CN102652922, 2012.

29 S. Herzog, S. Altwasser and K. J. Mueller-Engel, Process for Preparing Acrylic Acid from Methanol and Acetic Acid, US Pat., 2012/0071688(A1), 2012.

30 D. Nagaki, T. Pan and C. J. Peterson, Catalyst for Producing Acrylic Acid and Acrylates, US Pat., 2013/0245312(A1), 2013.
31 X. G. Kong, B. Hu and G. L. Zhuo, J. Mol. Catal., 2013, 27, 2329.

32 M. Turco, G. Bagnasco, C. Cammarano, P. Senese, U. Costantino and M. Sisani, Appl. Catal., B, 2007, 77, 46-57.

33 X. R. Chen and C. Y. Mou, J. Phys. Chem. C, 2007, 111, 1873118737.

34 A. Jia, J. Li, Y. Zhang, Y. Song and S. Liu, Mater. Sci. Eng., C, 2008, 28, 1117-1226.

35 L. F. Chen, L. E. Noreña, J. Navarrete and J. A. Wang, Mater. Chem. Phys., 2006, 97, 236-242.

36 B. Chakraborty and B. Viswanathan, Catal. Today, 1999, 48, 253-260.

37 G. Centi, G. Golinelli and G. Busca, J. Phys. Chem., 1990, 94, 6813-6819.

38 K. S. W. Sing, Pure Appl. Chem., 1985, 57, 603-619. 